\title{
Çalışma Hayatındaki Bireylerin Probiyotik Besinler Hakkındaki Bilgi Düzeyi ve Tüketim Durumlarının Belirlenmesi* $^{*}$
}

\author{
Aybala Ayça ÖZGÜL ${ }^{* * *}$, Cansu BOZAT ${ }^{* * * *}$, Merve SEZİ̧S ${ }^{* * * *}$, Yasemin BADUR ${ }^{* * * * * *}$, \\ Öznur Özge ÖZCAN ${ }^{* * * * * *}$, Esra Tansu SARIYER ${ }^{* * * * * * *}$, Ekin ÇEVIK ${ }^{* * * * * * * *}$, \\ Hatice ÇOLAK ${ }^{* * * * * * * * *}$, Mesut KARAHAN*********
}

\section{$\ddot{O} \mathbf{z}$}

Amaç: Son yıllarda yapılan çalışmalar probiyotiklerin sağlık üzerine olan etkilerini göstermekle beraber, bireylerin probiyotik bilgi düzeyi arttıkça tüketimin de arttığı gözlemlenmiştir. Bu

\section{Özgün Araştırma Makalesi (Original Research Article)}

Geliş / Received: 24.08 .2020 \& Kabul / Accepted: 13.11 .2020

DOI: https://doi.org/10.38079/igusabder.784094

${ }^{*}$ Bu makale, Aybala Ayça ÖZGÜL, Cansu BOZAT, Merve SEZİS, Yasemin BADUR'un 2020 yılında Öznur Özge ÖZCAN, Esra Tansu SARIYER, Ekin ÇEVİ, Hatice ÇOLAK, Doç. Dr. Mesut KARAHAN danışmanlığı ile Üsküdar Üniversitesi'nde lisans bitirme projesi olarak birlikte yürütülen bir anket çalışmasından üretilmiştir.

** Diyetisyen, İstanbul, Türkiye, E-posta: aybalaayca@gmail.com

ORCID https://orcid.org/0000-0003-0402-2269

*** Diyetisyen, İstanbul, Türkiye, E-posta: cansubzt@hotmail.com ORCID https://orcid.org/o0o0-0002-6393-7576

**** Diyetisyen, İstanbul, Türkiye, E-posta: sezismerve@gmail.com

ORCID https://orcid.org/0000-0002-9485-719X

****** Diyetisyen, İstanbul, Türkiye, E-posta: baduryasmin@gmail.com

ORCID https://orcid.org/o0oo-0002-7750-8879

****** Doktora Öğrencisi, Üsküdar Üniversitesi, Sağllk Bilimleri Enstitüsü, İstanbul, Türkiye,

E-posta: ozcannnozgee@ @otmail.com ORCID https://orcid.org/oooo-0001-8992-0556

******** Öğr. Gör., Üsküdar Üniversitesi, İstanbul, Türkiye,

E-posta: esratansu.sariyer@uskudar.edu.tr ORCID https://orcid.org/oooo-0001-7042-9185

${ }_{* * * * * * * * *}$ Ar. Gör., Üsküdar Üniversitesi, İstanbul, Türkiye, E-posta: ekin.cevik@uskudar.edu.tr ORCID https://orcid.org/0000-0003-1591-0069

Ar. Gör., Üsküdar Üniversitesi, İstanbul, Türkiye, E-posta: hatice.colak@uskudar.edu.tr

ORCID https://orcid.org/0000-0001-5502-8762

*********** Doç. Dr., Üsküdar Üniversitesi, İstanbul, Türkiye,

E-posta: mesut.karahan@uskudar.edu.tr ORCID https://orcid.org/oooo-0002-8971-678X 
çalışmanın amacı, sağlık personellerinin probiyotik besinler hakkında bilgi düzeyi ve tüketim durumlarının belirlenmesidir.

Yöntem: Bu çalışma, Aralık 2019 - Mayıs 2020 tarihleri arasında İstanbul İl Sağlık Müdürlüğüne bağlı iki Kamu hastanesinde rastgele seçilen, 18 yaş ve üzeri 25 sağlıklı gönüllü üzerinde yüz yüze anket ile veri toplama yöntemi kullanılarak yapılmıştır. Çalışma, yaş ortalaması 35,9 olan 14 kadın (\%56) ve 11 erkek (\%44) olmak üzere 25 birey ile tamamlanmıştır.

Bulgular: Katılımcıların \%96'sı probiyotik terimini bilmektedir. Probiyotik türlerini \%6o mayalar, \%60 Lactobacilllus türleri, \%44 Escherichia türleri, \%44 küfler, \%8 Bifidobacterium türleri olarak bilmekte \%8’i ise bilmemektedir. Tüm katılımcılar tarafından tüketilen probiyotik besin yoğurttur. Katılımcıların \%88'i kefir, \%60’ı turşu, \%52'si boza, \%20’si sirke, \%20'si kımız tüketmektedir. Katılımcıların \%96 her gün probiyotik gıda tüketmektedir. \%4 tüketmeyen kısım ise ihtiyaç duymadığından ve doğal olmadığını düşündüğünden tüketmemektedir.

Sonuç: Elde edilen veriler göz önüne alındığında, sağlık çalışanlarında probiyotik bilgi düzeyleri ve tüketimlerinin yüksek olduğu görülmüştür. Sağlık üzerine yararlı etkileri kanıtlanmış olan probiyotiklere yönelik farkındalığın ve tüketimin artırılması gerekmektedir. Probiyotik bilgi düzeyi ve tüketimi arasındaki ilişkinin açığa çıkması için daha fazla çalışmaya ihtiyaç duyulmaktadır.

Anahtar Sözcükler: Bilgi düzeyi, probiyotik, sağlık çalışanları, tüketim.

\title{
Determination of Knowledge Level and Consumption Status of Individuals in Working Life about Probiotic Foods
}

\begin{abstract}
Aim: Although studies conducted in recent years show the effects of probiotics on health, it has been observed that consumption increases as the level of knowledge of individuals increases. This study aims to determine the level of knowledge and consumption status of healthcare professionals about probiotic foods.

Method: This study was carried out by using a face-to-face questionnaire method on 25 healthy volunteers aged 18 and above, randomly selected in two public hospitals affiliated to Istanbul Provincial Health Directorate between December 2019 - May 2020. The study was completed on 25 individuals, 14 women (56\%), and 11 men (44\%) with an average age of 35,9.

Results: $96 \%$ of the participants know the term probiotic and $4 \%$ do not. They know probiotic species as 60\% yeasts, 60\% Lactobacillus species, 44\% Escherichia species, 44\% molds, 8\% Bifidobacterium species and $8 \%$ do not. The probiotic food consumed by all participants is yogurt.
\end{abstract}


$88 \%$ of the participants consume kefir, $60 \%$ pickles, $52 \%$ boza, $20 \%$ vinegar, $20 \%$ of kumis. $96 \%$ of the participants consume probiotic foods every day. The $4 \%$ does not consume it because they do not need it and think it is not natural.

Conclusion: Considering the data obtained, it was seen that the probiotic knowledge levels and consumption of healthcare workers were high. Awareness and consumption of probiotics with beneficial health effects need to be increased. More studies are needed to reveal the relationship between probiotic knowledge level and consumption.

Keywords: Knowledge level, probiotics, healthcare professionals, consumption.

\section{Giriş}

"Probiyotik" kelimesi Yunanca da "yaşam için" manasına gelmektedir ve uzun yıllardır birçok şekilde tanımlanmıştır. Günümüzdeki probiyotiklerin tarihi, 190o'lerde Rus bir bilim adamı ve Nobel ödüllü Elie Metchnikoff'un Paris'teki Pasteur Enstitüsü'ndeki ilk adımlarıyla başlamıştır. Fermantasyon terimi ise ilk Louis Pasteur tarafindan ortaya atılmıştır ${ }^{1}$.

Probiyotikler Dünya Sağlık Örgütü (WHO) ve Gıda ve Tarım Örgütü (FAO) tarafından tanımlanmıştır. 2014 yılında Uluslararası Probiyotik ve Prebiyotik Bilimsel Derneği tarafından yapılan gözden geçirme sonucunda, probiyotikler yeterli miktarda verildiğinde konağın sağlı̆̆ına yarar sağlayan canlı mikroorganizmalar olarak tanımlanmıştır. Lactobacillus türleri, Bifidobacterium türleri, Streptococcus türleri ve Sacchoromyces boulardi mayası probiyotik etkileriye bilinen başlıca mikroorganizmalardır².

Genel olarak güvenli olarak kabul edilen anlamına gelen GRAS terimi, Besin ve İlaç İdaresi (FDA) tarafından onaylanan bir beyandır. Amerika Birleşik Devletleri’nde mikroorganizmaların tüketim amaçlı kullanılabilmesi için GRAS beyanına sahip olması zorunluluğu bulunmaktadır³. Güvenli varsayın anlamına gelen QPS ise Avrupa Besin Güvenliği Otoritesi (EFSA) tarafından tanımlanan bir beyandır. Güvenli kullanım öyküsü, antibiyotiklere direnç göstermemesi veya direnç riskinin az olması gibi kriterler de dâhil olmak üzere QPS birçok güvenlik kriteri içermektedir². 
Her bakteri suşu probiyotik özellikte kabul edilmemektedir. Probiyotik olarak kabul edilebilmesi için; genetik olarak stabil olması, mide pH’sına dirençli olması, konakçı yani insan sağlı̆̆ında olumlu etkiler yaratması sağlaması, herhangi bir güvenlik endişesi taşımaması, safra tuzu ve sindirim enzimlerine karşı direnç göstermesi, raf ömrü bitene kadar üründe canlı olarak kalabilmesi gerekmektedir ${ }^{4}$. Son yıllarda yapılan çalışmalar probiyotiklerin sağlı üzerine yararlı etkileri olduğunu göstermektedir. Birçok çalışmadan elde edilen sonuçlar probiyotiklerin muhtemel dört mekanizma ile bu yararlı etkilerini sağladığını göstermektedir. Bu mekanizmalar, antimikrobiyal maddelerin üretimi yoluyla antagonizma, epitelyuma ve besin maddelerine yapışma için patojenlerle rekabet, konağın immünomodülasyonu ve bakteriyel toksin üretiminin inhibisyonudur. İnsanlar ve ratlar üzerinde yapılan çalışmalar probiyotiklerin, obezite, immün sistem hastalıkları, insülin direnci, tip 2 diyabetes mellitus, non-alkolik yağlı karaciğer hastalığı, irritabl barsak sendromu, inflamatuvar barsak hastalıkları, diyare, konstipasyon gibi gastrointestinal hastalıklar üzerine yararlı etkileri olabileceğini göstermiştir5,6.

Probiyotik özellikteki mikroorganizmalar, fermente bazı bitkisel ürünlerde, fermente bazı süt ürünlerinde, yoğurt, kefir, ayran, turşu, lahana, şalgam, boza, kımız, fermente et gibi besinlerde bulunabilmektedir ${ }^{7,8}$.

Probiyotiklerin sağlık üzerine yararlı etkileri de göz önüne alındığında, bireylerin probiyotik tüketimi ve probiyotik hakkındaki bilgi düzeylerinin ölçülmesi önem kazanmaktadır. Bu çalışmanın amacı, sağlık personellerinin probiyotik besinler hakkında bilgi düzeyi ve tüketim durumlarının belirlenmesidir.

\section{Gereç ve Yöntem}

Araştırma Yeri, Zamanı ve Örneklem Seçimi: Çalışma, Aralık 2019 - Mayıs 2020 tarihleri arasında İstanbul İl Sağlık Müdürlüğüne bağlı iki kamu hastanesinde rastgele seçilen, 18 yaş ve üzeri 25 sağlıklı gönüllü üzerinde yapılmıştır. Bu çalışma için 61351342/2020-99 saylı 27.02.2020 tarihli “Etik Kurul Onay” alınmıştır. 100 kişi üzerinde yapılması planlanan bu çalışma, İl Sağlık Müdürlüğü tarafından COVID-19 pandemisi sebebiyle akademik çalışmaların iptal edilmesine nedeniyle 25 çalışan ile sınırlı kalarak yüz yüze anket yöntemiyle veri toplanmıştır.

Verilerin Toplanması ve Değerlendirilmesi: Katılımcılara çoktan seçmeli ve açık uçlu soruları içeren bir anket formu araştırmacı tarafından yüz yüze görüşme tekniği ile 
doldurulmuştur. $\mathrm{Bu}$ anket formu 24 sorudan oluşmaktadır. Anket formunun ilk kısmında katılımcılara ait demografik veriler, yaşam tarzı, beslenme alışkanlıkları, kronik hastalık varlığı sorgulanmıştır. Katılımcıların boy uzunluğu ve vücut ağırlığı değerleri kendi beyanları doğrultusunda kaydedilmiştir. Anketin ilerleyen aşamalarında katılımcıların probiyotik besinler hakkındaki bilgi düzeyi, tüketim durumu ve nedenleri, tüketilen besinlerin sıklı̆̆ı ve probiyotik besinler hakkındaki öngörülerine yönelik ifadelerin bulunduğu tablo eklenmiştir. Katılımcıların probiyotiklere bilgi düzeyleri ve öngörülerinin sorgulandığı anket tablosunda probiyotiklerin özelliklerine yönelik 12 tane sorgu cümlesi yer almakta olup, cevaplar "katılmıyorum", "kararsızım" ve "katılıyorum" olarak kategorize edilmiştir. Araştırmada elde edilen verilerin analizinde yüzde hesaplama yöntemi kullanılmıştır. Araştırmaya katılan kişiler "Bilgilendirilmiş Gönüllü Onam Formu"nu imzalamıştır. Araştırma 14 kadın (\%56) ve 11 erkek (\%44) olmak üzere 25 birey ile tamamlanmıştır.

\section{Bulgular}

Araştırma 14 kadın (\%56) ve 11 erkek (\%44) olmak üzere 25 birey ile tamamlanmıştır. Katılımcıların ağırlık ortalaması $69,68 \mathrm{~kg}$, boy ortalaması 168,76 cm ve yaş ortalaması 35,9'dur. Katılımcıların \%88'lik kısmının beslenmeye bağlı tanısı konulmuş hastalığı vardır. Bu hastalıkların \%32'si anemi, \%32'si diyabet, \%36’sı obezitedir.

Katılımcıların \%96'sı probiyotik terimini bilmektedir. Katılımcıların probiyotik türleri hakkındaki bilgi düzeyleri incelendiğinde ise, \%60’ının mayaları, \%60'ının Lactobacillus türlerini, \%44'ünün Escherichia türlerini, \%44’ünün küfleri, \%8’inin ise Bifidobacterium türlerini bildiği görülmüştür. Tüm katılımcılar tarafından tüketilen probiyotik besin yoğurt olarak bildirilmiştir. Katılımcıların \%88’i kefir, \%60’ı turşu, \%52'si boza, \%20’si sirke, \%20’si kımız tüketmektedir. Katılımcıların \%96’sı her gün probiyotik besin tüketmektedir. Tüketmeyen bireyler ise ihtiyaç duymadığından ve doğal olmadığını düşündüğünden tüketmemektedir. Günlük probiyotik gıda tüketen katılımcıların \%83,3’ü sindirim sorunları ve bağırsak sağlı̆̆ına etkisi nedeniyle, \% 62,5’i enfeksiyonlara karşı koruyucu olduğundan, \%41,7'si tavsiye üzerine, \%4,2'si antibiyotik kullandığından ve \%4,2’si ise reklamların etkisiyle tükettiğini belirtmiştir. Katılımcıların probiyotikler hakkındaki bilgi düzeyi ve tüketim durumları Tablo 1'de gösterilmiştir. 
Tablo 1. Probiyotik Besinler Hakkındaki Bilgi Düzeyi ve Tüketim Durumlarının Değerlendirilmesi

\begin{tabular}{|c|c|c|c|}
\hline & & $\mathbf{n}$ & $\%$ \\
\hline \multirow[t]{2}{*}{ Probiyotik terimini bilme durumu } & Biliyorum & 24 & 96 \\
\hline & Bilmiyorum & 1 & 4 \\
\hline \multirow{6}{*}{$\begin{array}{l}\text { Probiyotik türlerini tanıma bilme } \\
\text { durumu }\end{array}$} & Escherichia türleri & 11 & 44 \\
\hline & Lactobacillus türleri & 15 & 60 \\
\hline & Bifidobacterium türleri & 6 & 24 \\
\hline & Mayalar & 15 & 60 \\
\hline & Küfler & 11 & 44 \\
\hline & Bilmiyorum & 2 & 8 \\
\hline \multirow[t]{6}{*}{ Tüketilen probiyotik besinler } & Yoğurt & 25 & 100 \\
\hline & Turşu & 15 & 60 \\
\hline & Kefir & 22 & 88 \\
\hline & Sirke & 5 & 20 \\
\hline & Kimız & 5 & 20 \\
\hline & Boza & 13 & 52 \\
\hline \multirow{2}{*}{$\begin{array}{l}\text { Günlük probiyotik besin tüketme } \\
\text { durumu }\end{array}$} & Tüketiyorum & 24 & 96 \\
\hline & Tüketmiyorum & 1 & 4 \\
\hline \multirow{6}{*}{$\begin{array}{l}\text { Probiyotik besin tüketilmemesinin } \\
\text { sebepleri }\end{array}$} & Doğal olmaması & 1 & 50 \\
\hline & Pahalı olması & - & - \\
\hline & Tadının beğenilmemesi & - & - \\
\hline & İhtiyaç duyulmaması & 1 & 50 \\
\hline & İçeriğinin güvenli gelmemesi & - & - \\
\hline & $\begin{array}{l}\text { Tam olarak ne işe yaradığının } \\
\text { bilinmemesi }\end{array}$ & - & - \\
\hline
\end{tabular}




\begin{tabular}{|c|c|c|c|}
\hline \multirow[t]{5}{*}{$\begin{array}{l}\text { Probiyotik gıda tercihinde etkili olan } \\
\text { faktörler }\end{array}$} & $\begin{array}{l}\text { Sindirim sorunları ve bağırsak } \\
\text { sağlığına etkisi }\end{array}$ & 20 & 83,3 \\
\hline & Antibiyotik kullanma durumu & 1 & 4,2 \\
\hline & $\begin{array}{l}\text { Enfeksiyonlara karşı koruyucu } \\
\text { olması }\end{array}$ & 15 & 62,5 \\
\hline & $\begin{array}{l}\text { Reklamlar (sosyal medya, tv, } \\
\text { vb.) }\end{array}$ & 1 & 4,2 \\
\hline & $\begin{array}{l}\text { Tavsiye üzerine (arkadaş, } \\
\text { doktor, diyetisyen) }\end{array}$ & 10 & 41,7 \\
\hline \multirow{2}{*}{$\begin{array}{l}\text { Probiyotik ürün takviyesi kullanımı } \\
\text { (kapsül, toz, hap vs.) }\end{array}$} & Evet, kullaniyorum. & 5 & 20 \\
\hline & Hayır, kullanmıyorum. & 20 & 80 \\
\hline \multirow{2}{*}{$\begin{array}{l}\text { Probiyotik besin veya probiyotik } \\
\text { ürünleri faydalı görme durumu }\end{array}$} & Faydasını gördüm. & 25 & 100 \\
\hline & Faydasını görmedim. & - & - \\
\hline \multirow{6}{*}{$\begin{array}{l}\text { Probiyotiklerin hangi hastalığa iyi } \\
\text { geldiğini düşünme durumu }\end{array}$} & İshal & 15 & 60 \\
\hline & Kabızlık & 21 & 84 \\
\hline & Alerji ve Bağışıklık Sistemi & 7 & 28 \\
\hline & Şişkinlik ve hazımsızlık & 13 & 52 \\
\hline & $\begin{array}{l}\text { İnflamatuar Bağırsak } \\
\text { Hastalıkları }\end{array}$ & 9 & 36 \\
\hline & Kolesterol yüksekliği & 1 & 4 \\
\hline \multirow{2}{*}{$\begin{array}{l}\text { Probiyotikleri çevredeki kişilere tavsiye } \\
\text { etme durumu }\end{array}$} & Tavsiye ederim. & 25 & 100 \\
\hline & Tavsiye etmem. & - & - \\
\hline
\end{tabular}

Probiyotik besinlerin tüketim sıklığına bakıldığında katılımcıların \%56'sı haftada 2-3 kez, \%32'si haftada 1 kez, \%12'si haftada 2-3 kez probiyotik gıda tüketmektedir. Probiyotik ürün takviyesi alımında katılımcıların \%80’i takviye almamaktadır. Takviye alan katılımcıların tamamı probiyotik takviyesinin faydasını görmüsstür. Katılımcıların \%84'ü kabızlık, \%60’ı ishal, \%52'si şişkinlik ve hazımsızlık, \%36’sı inflamatuar bağırsak 
hastalıkları, \%28'si alerjiler ve bağışıklık sistemini güçlendirme, \%4’ü ise kolesterol yüksekliğine faydalı olduğundan probiyotik ürün tüketmeyi tercih etmektedir. Katılımcıların tamamı probiyotik ürün tüketmeyi çevresindekilere tavsiye ettiğini belirtmiştir.

Katılımcıların probiyotikle ilgili görüşleri değerlendirildiğinde; \%40’ı probiyotiklerin kolon kanseri riskini azalttığını düşünürken, \%52'si kararsız, \%2'si katılmıyorum olarak cevap vermiştir. Katılımcıların \%20’si kilo kaybı için probiyotik kullanılması gerektiğini, \%14'ü ise gerekmediğini düşünmektedir. Katılımcıların \%84’ü probiyotiklerin enfeksiyonla mücadelede etkili olacağını düşünmektedir. Katılımcıların probiyotiklerle ilgili görüşleri Tablo 2'de özetlenmiştir.

Tablo 2. Probiyotiklerle İlgili Görüşler

\begin{tabular}{|l|c|c|c|c|c|c|}
\hline & \multicolumn{2}{|l}{ Katılyorum } & \multicolumn{2}{l|}{ Kararsızım } & \multicolumn{2}{l|}{ Katılmıorum } \\
\hline & $\mathbf{n}$ & $\%$ & $\mathbf{n}$ & $\%$ & $\mathbf{n}$ & $\%$ \\
\hline $\begin{array}{l}\text { Probiyotikler immün sistemi } \\
\text { güçlendirir. }\end{array}$ & 23 & 92 & 2 & 8 & - & - \\
\hline $\begin{array}{l}\text { Probiyotikler enfeksiyonlarla } \\
\text { mücadele eder. }\end{array}$ & 21 & 84 & 4 & 32 & - & - \\
\hline Probiyotikler kabızlığı tedavi eder. & 24 & 96 & 1 & 4 & - & - \\
\hline $\begin{array}{l}\text { Probiyotikler (diyare) ishali tedavi } \\
\text { eder. }\end{array}$ & 20 & 80 & 4 & 16 & 1 & 4 \\
\hline $\begin{array}{l}\text { Probiyotikler kolon kanserini önler. } \\
\text { Probiyotikler tüm kanser } \\
\text { tedavilerinde kullanılmalıdır. }\end{array}$ & 10 & 40 & 13 & 52 & 2 & 8 \\
\hline $\begin{array}{l}\text { Probiyotikleri çocuklar da } \\
\text { kullanmalıdır. }\end{array}$ & 21 & 84 & 4 & 16 & - & - \\
\hline $\begin{array}{l}\text { Probiyotikleri yaşlılar da } \\
\text { kullanmalıdır. }\end{array}$ & 22 & 88 & 3 & 12 & - & - \\
\hline $\begin{array}{l}\text { Probiyotikler kilo vermek için } \\
\text { kullanılmalıdır. }\end{array}$ & 5 & 20 & 6 & 24 & 14 & 56 \\
\hline
\end{tabular}




\begin{tabular}{|l|c|c|c|c|c|c|}
\hline $\begin{array}{l}\text { Probiyotikler kolesterol seviyesini } \\
\text { düzenler. }\end{array}$ & 8 & 32 & 14 & 56 & 3 & 12 \\
\hline $\begin{array}{l}\text { Probiyotik içeren besinler fazla } \\
\text { sayıda yararlı mikroorganizma } \\
\text { içerir. }\end{array}$ & 20 & 80 & 4 & 16 & 1 & 4 \\
\hline $\begin{array}{l}\text { Probiyotikler antibiyotiklerle } \\
\text { birlikte kullanılmalıdır. }\end{array}$ & 13 & 52 & 7 & 28 & 5 & 20 \\
\hline
\end{tabular}

\section{Tartışma}

Günümüzde sağlıklı beslenme farkındalığının artışına paralel olarak besin destekleri kullanımı da artmaya başlanmıştır. Fonksiyonel besinler, temel beslenmenin yanı sıra insan fizyolojisi ve metabolik fonksiyonları üzerinde ilave faydalar sağlayan besinlerdir. Bu faydaları sayesinde, hastalıklardan korunmada ve daha sağlıklı bir yaşama ulaşmada etkinlik göstermektedirler. Probiyotikler de fonksiyonel besinler içerisinde önemli role sahiplerdir 9 .

Garcia ve ark. 2018 yılında 1328 sağlık çalışanında (\%36’sı gastroenterolog, \%46’sı beslenme uzmanı, \%18'si kimyager ve mikrobiyolog) çevrimiçi anket yöntemiyle yaptığı bir çalışmada, katılımcıların \%75’inin FAO tarafından yapılmış probiyotik tanımını bildiği, gastroenterolog ve beslenme uzmanlarının sırasıyla \%96’sının ve \%98’inin probiyotikleri gastrointestinal semptom yönetiminde başarılı bulduğu gözlemlenmiştir. Ayrıca bu çalışmada katılımcıların çoğu ticari probiyotik ürünlerde hangi probiyotik suşunun bulunduğunu bilmediği saptanmıştır ${ }^{10}$. Sağlık çalışanlarında probiyotik farkındalığı ve bilgi değerlendirilmesi amacıyla 221 sağlık çalışanı üzerinde yapılan başka bir çalışmada, katılımcıların \%72,4'ü probiyotik teriminden haberdar olduklarını, ancak sadece \%25,8'inin herhangi bir probiyotik ürünün kullanılmasını önerdiğini belirtmiştir. Probiyotik farkındalığı yüksek olan katılımcıların \%36,9'u eczacı, \%28’i doktor, \%20’si hemşire ve \%14,4'ü diş hekimidir. Katılımcıların tamamı probiyotik hakkında daha fazla bilgiye ihtiyaç duyduğunu belirtmiştir ${ }^{11}$. Zemzemoğlu ve ark. tarafından geleceğin sağlık çalışanları olacak olan, Sağlık Bilimleri Fakültesi öğrencilerine yapılan bir çalışmada ( $n=1287)$, öğrencilerin \%55,6'sı probiyotik terimini bildiği, \%46,1’i ise probiyotik tükettiği, 87,7'si ise probiyotik besin tükettiği bulmuşlardır. Katılımcıların \%91,3’ü ise 
probiyotiklerin sağlık üzerine yararlı etkileri olduğunu düşünmektedir ${ }^{12}$. 2019 yılında 30 ülkeden 1066 sağlık çalışanında çevrimiçi anket yöntemiyle yapılan bir çalışmada, katılımcıların \%8,7'si probiyotik bilgilerini mükemmel olarak değerlendirirken, \%36,4’ü orta, \%36,2'si iyi olarak değerlendirmiştir. Katılımcıların \%80’inden fazlası ise probiyotik tanımını doğru bilmektedir. Genel olarak sağlık çalışanlarının orta düzeyde probiyotik bilgisine sahip olduğu saptanan bu çalışmada, katılımcıların \%57'si probiyotikler hakkında daha fazla bilgi edinmek istemiştir ${ }^{13}$. Aslan ve ark. tarafından yetişkinlerde yapılan bir çalışmada, katılımcıların \%46,8’inin probiyotik ürünler hakkında bilgi sahibi olduğunu, \%26’sının probiyotik ürün kullandığını ve probiyotik ürün kullananlardan \%79,1’inin ise fayda gördüğünü düşündüğü bulunmuştur ${ }^{14}$. Nijerya'da tıp bilimleri öğrencileri $(n=164)$ ve sağlık çalışanlarında (n=101) yapılan başka bir çalışmada, öğrencilerin \%57,3’ünün probiyotik terimini duymadıkları, sağlık çalışanlarının ise \%69,3'ünün probiyotik terimini bildikleri saptanmıştır5. Yetişkin bireylerin probiyotik besinler hakkındaki bilgi düzeylerini ve tüketim durumlarını belirlemek amacıyla Türkiye'de 117 yetişkin üzerinde yapılan bir çalışmada, katılımcıların \%66,5’inin probiyotik terimini bildiği, \%64,2'sinin probiyotik besin tükettiği, \%3,9'unun probiyotik takviye tükettiği gözlemlenmiştir. Ayrıca çalışmaya katılan bireylerin \%51,4'ünün günde 1 kez yoğurt, \%7,5’inin haftada 1 kez kefir tükettikleri ve en çok bilinen probiyotik besinin ise yoğurt olduğu saptanmıştır ${ }^{16}$. Türkiye'de sağlık çalışanlarında probiyotik kullanımları hakkında bilgi, tutum ve davranışlarının incelendiği bir çalışmada $(n=306)$, probiyotik genel bilgi düzeylerini aile hekimlerinin \%67,4’ü orta, \%16,3’ü kötü, pediatristlerin \%59,5’i orta, \%36,5’i kötü olarak değerlendirilirken, eczacıların \%70’i probiyotiklerin içindeki mikroorganizmaları bildiğini belirtilmiştir. Buna ek olarak, probiyotik kullanımının eczacılar arasında yaygın olduğu görülmüştür ${ }^{17}$. Anukam ve ark. tarafından 62 klinisyen üzerinde yapllan bir çalışmada, katılımcıların \%95,2'si probiyotik terimini bilmediğini ifade etmiştir. Kağan ve ark. tarafından 2019 yılında yetişkinlerde yapılan bir çalışmada ( $\mathrm{n}=110)$, katılımcıların \%64,5’i probiyotik besin terimini bildiğini, \%73,6’sı probiyotik besin tükettiklerini, \%64,3’ü probiyotik tüketimini bağışıklık sistemi aktivasyonunda etkili olduğunu düşündüklerini belirtmişlerdir ${ }^{18}$. Sağlık çalışanlarında probiyotik ve prebiyotik bilgisi incelenmesi amaçlanan bir çalışmada (n=256), katılımcıların \%88’inin probiyotik terimine aşina olduğu, \%62'sinin ise probiyotiklerin sağlığa biraz faydalı olduğunu 
düşündüğü, \%45’inin hastalarına probiyotik önermedikleri görülmüştür ${ }^{19}$. Taş ve ark. tarafından 340 sağlık personeli (\%66,2 doktor ve \%33,8 hemşire) üzerinde yapılan bir çalışmada, katılımcıların \%80’i probiyotik besin veya ürünleri tedavi amaçlı önerdiğini, en fazla önerdikleri probiyotik besinin \%66,2 ile kefir olduğunu belirtmişlerdir ${ }^{20}$. Hindistan'da 267 sağlık çalışanı üzerinde yapılan çalışmada, katılımcıların çoğunun $(\% 93,25)$ probiyotik teriminden haberdar olduğu, \%54,68’inin ise sağlık üzerine yararlı etkilerini bildikleri saptanmıştır. Ayrıca, katılımcıların \%50’si probiyotik besinleri, probiyotik ilaçlara tercih ettiklerini belirtmişlerdir ${ }^{21}$. Kanada'da sağlık çalışanlarında yapılan başka bir çalışmada, katılımcıların sadece \%18'inin probiyotikler hakkında bilgi sahibi olduğu görülmüştür ${ }^{22}$. Bu çalışmada da katılımcıların \%96'sının probiyotik terimini bildiği, \%8’inin ise probiyotik suşu türlerini bilmediği bulunmuştur. Buna ek olarak, katılımcıların \%92'si probiyotiklerin immün sistemi güçlendirdiğini, \%20'si kolon kanserine karşı koruyucu olduğunu, \%20'si kilo vermede etkili olduğunu, \%96'sı ise konstipasyon tedavisinde etkin olduğunu düşündügüüü beyan etmişlerdir.

Köse ve ark. tarafından yapılan bir çalışmada ( $n=130)$, sağlık çalışanlarının \%47,3’ünün, sağlık çalışanı olmayan bireylerin ise \%52,7'sinin probiyotik besin tükettiği bulunmuştur. Tüketme nedenleri sorulduğunda ise sağlık çalışanlarının \%55,9'u bağışıklık sistemi güçlendirici, \%52,3’ü kansere karşı koruyucu etkisi nedeniyle tükettiklerini belirtmişlerdir. Sağlık çalışanlarında, diğer bireylere göre probiyotik ürün olarak yoğurt ve ayran tüketimi daha yüksek bulunmuştur ${ }^{9}$ ( $\mathrm{p}=0.00$ ). 2015 yılında 200 yatan hastada yapılan bir çalışmada, hastaların \%43’ünün probiyotik terimini bildiğini ve en çok tüketilen probiyotik ürünün yoğurt (\%72) olduğunu belirtmişlerdir²3. Brezilya'da yapılan probiyotik besinlere yönelik algı ve tutumların değerlendirildiği bir çalışmada (n=420), katılımcıların \%29,05’inin probiyotik besinleri doğru tanımladıkları, \%27,6'sının süt, \%25,7'sinin yoğurt ve \%13,3'ünün peynir tükettiği bulunmuştur²4. Hacıŏ̆lu ve Kurt tarafından yapılan çalışmada ise, katılımcılar tarafından en çok tüketilen besinin kefir (\%41) ve yoğurt (\%26) olduğu gözlemlenmiştir²5. Bu çalışmada, katılımclların tamamı probiyotik besin olarak yoğurt tükettiğini, \%88’i kefir, \%20’si kımız, \%52'si boza tükettiklerini belirtmişlerdir. Buna ek olarak, katılımcıların \%20’si probiyotik takviyesi (kapsül, toz, hap vs.) kullandığı ve katılımcıların beyanlarına göre tamamının kullanımdan fayda gördüğü saptanmıştır. 


\section{Sonuç}

Son yıllarda yapılan çalışmalar, probiyotiklerin birçok mekanizma ile sağlık üzerine olan yararlı etkilerini göstermektedir. Bu bağlamda, probiyotik besin ve takviye tüketimi önem kazanmaktadır. Literatürdeki birçok çalışmada, probiyotik bilgi düzeyi arttıkça, probiyotik besin ve ürün kullanımının arttığı görülmektedir. Bu çalışma, sağllk çalışanlarında probiyotik bilgi düzeyi ve tüketimi arasındaki ilişkiyi ortaya koymaktadır. Bunun yanı sıra, COVID-19 pandemisi nedeniyle örneklem sayısının planlanandan düşük kalması, çalışmanın sınırllıklarındadır. Probiyotik bilgi düzeyi ve tüketimi arasındaki ilişkinin açığa çıkarılması için daha fazla çalışmaya ihtiyaç duyulmaktadır.

\section{KAYNAKLAR}

1. Gasbarrini G, Bonvicin ĠF, Gramenzi A. Probiotics history. J. Clin. Gastroenterol. 2016;50:116-119.

2. Hill C, Guarner F, Reid G, et al. Expert consensus document: The International Scientific Association for Probiotics and Prebiotics consensus statement on the scope and appropriate use of the term probiotic. Nat Rev Gastroenterol Hepatol. 2014;11(8):506-514.

3. The European Food Safety Authority. Update of the list of QPS-recommended biological agents intentionally added to food or feed as notified to EFSA 7: suitability of taxonomic units notified to EFSA until September 2017. http://www.efsa.europa.eu/en/efsajournal/pub/5131 Yayınlanma tarihi 2017. Erişim tarihi 20 Haziran 2020.

4. Binns N. Probiotics, prebiotics and the gut microbiota. ILSI Europe. 2013:1-32.

5. Markowiak P, Śliżewska K. Effects of probiotics, prebiotics, and synbiotics on human health. Nutrients. 2017;9(9):1021-1051.

6. Daliri EB-M, Lee BH. New perspectives on probiotics in health and disease. Food Sci Hum Well. 2015;4(2):56-65.

7. Bell V, Ferrão J, Fernandes T. Nutritional guidelines and fermented food frameworks. Foods. 2017;6(8):65-82.

8. Aksu FY, Altunatmaz SS, Kahraman T. Probiyotik gıdalar ve insan sağllğı üzerine etkileri. ABMYO Dergisi. 2010;19:90-94. 
9. Köse B, Aydın A, Özdemir M, Yeşil E. Sağlık çalışanlarının probiyotik, prebiyotik ve sinbiyotikler hakkındaki bilgi düzeyinin ve tüketim durumlarının belirlenmesi. Akad Gastroent Derg. 2019;12(2):67-72.

10. Valdovinos-García L, Abreu A, Valdovinos-Díaz M. Probiotic use in clinical practice: results of a national survey of gastroenterologists and nutritionists. Rev Gastroenterol Mex (English Edition). 2019;84(3):303-309.

11. Otuto Amarauche C. Assessing the awareness and knowledge on the use of probiotics by healthcare professionals in Nigeria. $J$ Young Pharm. 2015;8(1):5355 .

12. Arpa Zemzemoğlu T, Uludağ E, Uzun S. Üniversite öğrencilerinin probiyotik bilgi düzeyi ve tüketim durumlarının belirlenmesi. J Food Sci. 2019;118-130.

13. Fijan, S, Frauwallner A, Varga L, et al. Health professionals' knowledge of probiotics: an international survey. Int J Environ Res Public Health. 2019;16(17):3128-3144.

14. Aslan S, Kara R, Yaman H. Probiyotik ürünlerin tüketim alışkanlıklarının belirlenmesi. Turk J Agric Food Sci Technol. 2019;7(6):861-865.

15. Chukwu E, Nwaokorie F, Yisau J, Coker A. Assessment of the knowledge and perception of probiotics among medical science students and practitioners in Lagos state. Br J Med Med Res. 2015;5(10):1239-1246.

16. Zeren R. Yetişkin Bireylerin Probiyotik Besinler Hakkında Bilgi Düzeyi ve Tüketim Durumlarının Belirlenmesi [yüksek lisans tezi]. İstanbul: Beslenme ve Diyetetik Bölümü, Haliç Üniversitesi Sağlık Bilimleri Enstitüsü; 2015.

17. Altındiş M, İnci MB, Elmas B ve ark. Aile hekimleri, pediatristler ve eczacıların probiyotik kullanımları hakkında bilgi, tutum ve davranışları. J. BSHR. 2018;2(2):108-116.

18. Arduzlar Kağan D, Özlü T, Yurttaş H. Yetişkin bireylerin probiyotik gıdaları bilme ve tüketme durumları üzerine bir araştırma. Eur J Lipid Sci Technol. 2019;(17):556-563.

19. Oliver L, Rasmussen H, Gregoire M, Chen Y. Health care provider's knowledge, perceptions, and use of probiotics and prebiotics. Top Clin Nutr. 2014;29(2):139-149. 
20. Gelmez Taş B, Zeren Öztürk G, Maç Ç, Egici M, Toprak, D. Cross-sectional study on microbiota and probiotic with health workers. $J$ Res Nurs. 2020;6(1):1-7.

21. Soni R, Tank K, Jain, N. Knowledge, attitude and practice of health professionals about probiotic use in Ahmedabad, India. Nutr Food Sci. 2018;48(1):125-135.

22. Edmunds L. The underuse of probiotics by family physicians. CMAJ. 2001;164(11):1577.

23. Betz M, Uzueta A, Rasmussen H, Gregoire M, Vanderwall C, Witowich G. Knowledge, use and perceptions of probiotics and prebiotics in hospitalised patients. Nutr Diet. 2015;72(3):261-266.

24. Viana J, Da Cruz A, Zoellner S, Silva R, Batista, A. Probiotic foods: consumer perception and attitudes. Int J Food Sci. 2008;43(9):1577-1580.

25. Hacıŏ̆lu G, Kurt G. Tüketicilerin fonksiyonel gıdalara yönelik farkındalığı, kabulü ve tutumları: Izmir ili örneği. J Bus Econ. 2012;3(1):161-171. 